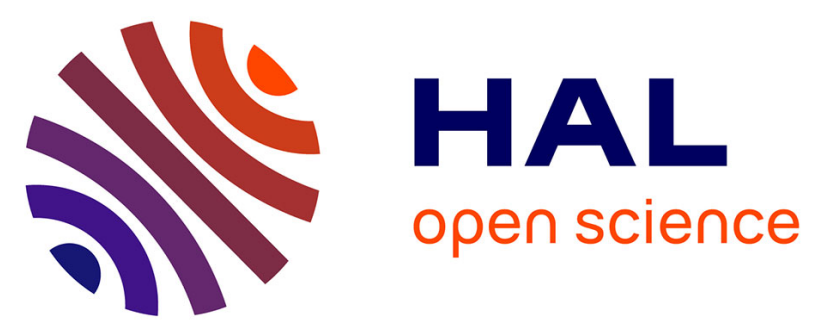

\title{
Classification of ice crystal shapes in midlatitude ice clouds from three years of lidar observations over the SIRTA observatory
}

\author{
Vincent Noel, Hélène Chepfer, Martial Haeffelin, Yohann Morille
}

\section{- To cite this version:}

Vincent Noel, Hélène Chepfer, Martial Haeffelin, Yohann Morille. Classification of ice crystal shapes in midlatitude ice clouds from three years of lidar observations over the SIRTA observatory. Journal of the Atmospheric Sciences, 2006, 63, pp.2978-2991. hal-00115274

\author{
HAL Id: hal-00115274 \\ https://hal.science/hal-00115274
}

Submitted on 20 Nov 2006

HAL is a multi-disciplinary open access archive for the deposit and dissemination of scientific research documents, whether they are published or not. The documents may come from teaching and research institutions in France or abroad, or from public or private research centers.
L'archive ouverte pluridisciplinaire HAL, est destinée au dépôt et à la diffusion de documents scientifiques de niveau recherche, publiés ou non, émanant des établissements d'enseignement et de recherche français ou étrangers, des laboratoires publics ou privés. 


\title{
Classification of ice crystal shapes in midlatitude ice clouds from three years of lidar observations over the SIRTA observatory
}

\author{
Vincent Noel $^{(1)}$, Helene Chepfer ${ }^{(2)}$, Martial Haeffelin ${ }^{(3)}$, Yohann Morille ${ }^{(3)}$ \\ (1) Analytical Services and Materials, Hampton, VA, USA \\ (2) Institut Pierre-Simon Laplace/Laboratoire de Meteorologie Dynamique, Université \\ Pierre et Marie Curie, Paris, France \\ (3) Institut Pierre-Simon Laplace/Laboratoire de Meteorologie Dynamique, Ecole \\ Polytechnique, France
}

2005-11-25

First submitted to the Journal of Atmospheric Sciences on 2005-04-18

Revised manuscript submitted on 2005-11-25

Corresponding Author:

Vincent Noel

Laboratoire de Météorologie Dynamique

Ecole Polytechnique

91128 Palaiseau, France

vincent.noel@,1md.polytechnique.fr 


\section{Abstract}

This paper presents a study of ice crystal shapes in midlatitude ice clouds inferred from a technique based on the comparison of ray-tracing simulations with lidar depolarization ratio measured at $532 \mathrm{~nm}$. This technique is applied to three years of lidar depolarization ratio observations from the SIRTA (Site Instrumental de Recherche par Télédétection Atmosphérique) observatory in Palaiseau, France, amounting to 322 different days of ice cloud observations. Particles in clouds are classified in three major groups : plates, columns, and irregular shapes with aspect ratios close to unity. Retrieved shapes are correlated with radiosounding observations from a close-by meteorological station: temperature, relative humidity, wind speed and direction.

Results show a strong dependence of the relative concentration of different crystal shapes to most atmospheric variables, such as the temperature, with a clear successive dominance by plate-like (temperature above $-20^{\circ} \mathrm{C}$ ), irregular (temperatures between $-60^{\circ} \mathrm{C}$ and $-40^{\circ} \mathrm{C}$ ), and column-like shapes (temperatures below $-60^{\circ} \mathrm{C}$ ). Particle shapes are almost exclusively column-like below $-75^{\circ} \mathrm{C}$. This is in sharp contrast with previous results of the same classification applied to tropical clouds, and highlights the high geographic variability of the ice clouds distribution of microphysical properties. Results also suggest that ice clouds created by jet streams (identified by high wind speeds) are strongly dominated by column-like shapes, while front-created ice clouds (identified by lower wind speeds) show a much more variable mix of shapes, with the dominant shapes depending on other factors. Results also suggest different microphysical properties according to the average direction source of air masses and winds. Following these results, a possible parameterization of ice crystal shapes in midlatitude ice clouds as a function of temperature is provided. 


\section{Introduction}

Ice clouds permanently cover as much as $40 \%$ of the Earth's surface (Liou, 1986). Moreover, recent satellite and ground-based observations suggest the coverage from subvisible ice clouds, which are hard to detect through conventional methods, may increase this to more than 50\% (Wang et al. 1996, Sassen and Campbell, 2001). This large spatial coverage makes them one of the major influences in the climate evolution, and a correct estimation of their radiative impact is essential to adequately reproduce and predict the climate (Cess et al., 1990, 1996). This radiative impact depends on the poorly known balance between their albedo and greenhouse effect, which is highly influenced by each cloud local microphysical properties (Sassen et al, 1989; Stephens et al., 1990). To improve their parameterization in general circulation models, a better understanding of these microphysical properties is essential (Sun and Shine, 1995). Among these, the shape of ice particles remains one of the major sources of uncertainties, which could modify ice cloud albedo by as much as $30 \%$ (Takano and Liou, 1989). The modeled bidirectional reflectance of ice clouds, which describes how incoming sunlight is redistributed in space through scattering, is also highly sensitive to the assumed shape of ice crystals (Yang et al., 2001): using incorrect shapes for ice clouds in optical depth retrieval algorithms can modify results by a factor of 3 (Mishchenko et al., 1996). Moreover, crystal shapes in ice clouds were recently found to influence subsequent ice formation processes, leading to a feedback effects on the cloud microphysical and radiative properties (Sassen et al., 2003). In the past two decades, in situ observations from intensive field campaigns, such as the first and second International Satellite Cloud Climatology Project (ISSCP) Regional Experiment (FIRE I and II), the European Cloud and Radiation Experiment (EUCREX), the International Cloud Experiment (ICE)... have all exposed the high spatial and temporal variability of this parameter, and shown it to be one of the most difficult to study (Cox et al. 1990, Francis et al. 1994, Sauvage et al. 1999). Moreover, recent field 
campaigns in the tropics such as the Cirrus Regional Study of Tropical Anvils and cirrus Layers - Florida Area Cirrus Experiment (CRYSTAL-FACE, Jensen et al. 2004) concluded that ice crystals in convective ice clouds exhibit different properties from those generally assumed in most climate models (Heymsfield et al, 2002a ; Garrett et al., 2003). Several studies have tried to retrieve particle shape using observations from spaceborne instruments, such as the Moderate Resolution Imaging Spectroradiometer (MODIS, Rolland et al. 2000) and Polarization and Directionality of Earth's Reflectance (POLDER, Chepfer et al. 1999, 2001, Masuda et al. 2002). However, radiometric observations from satellite suffer from the limitations of passive remote sensing: on one hand, the lower limit of detection for optically thin clouds is not well known, which means the entire population of subvisible ice clouds (potentially more than $20 \%$, Goldfarb et al. 2001) may be overlooked; on the other hand, the vertical distance on which the observed quantities are integrated is still unclear. A way to overcome these limitations is to use active remote sensing (Chiriaco et al 2004).

The present study uses observations of linear depolarization ratio to retrieve information on the shape of particles inside ice clouds, using an already-published shape classification technique (Noel et al, 2002). Three years of observations are considered, leading to an extensive study of ice crystal shapes that could be considered representative of midlatitude ice clouds. Retrieved information about shapes is correlated with atmospheric variables : temperature, relative humidity, wind speed and direction. Results are compared with shape information previously retrieved in midlatitude and tropical ice clouds using lidar and in-situ probes.

The instrument used in this study is first presented in Sect. 2, with a short description of the shape classification technique. The ice clouds lidar depolarization ratio dataset is then introduced in Sect. 3, along with the variability of atmospheric variables for the studied cases. Results of the shape classification and their correlation with radiosounding variables are 
presented in Sect. 4. Results are discussed and conclusion is given in Sect. 5.

\section{Ice crystal shape information from lidar depolarization}

\section{ratio}

The high sensitivity of the lidar instrument to optically thin clouds makes it one of the instruments best suited to the study of ice clouds (Platt, 1973), especially when equipped to monitor the state of light polarization (Sassen 1991). In this last configuration, the emitted beam of laser light is linearly polarized in a specific plane. The linear depolarization ratio $\delta=\frac{I_{\perp}}{I_{\|}}$is then defined as the ratio of backscattered light intensities in the planes perpendicular $\left(I_{\perp}\right)$ and parallel $\left(I_{/ /}\right)$to the plane of emission. This ratio $\delta$ has been shown to be extremely sensitive to the microphysical properties of probed clouds (Chen et al. 2002), and especially particle shape (Sassen, 1977). The present study uses a technique that classifies particle shapes in ice clouds by comparing observed depolarization ratios with results of a ray-tracing simulation (extensively described in Noel et al. 2001). The simulation follows modifications in light polarization as it travels through modeled hexagonal-based ice crystals, so the evolution of $\delta$ can be studied as a function of three parameters: the particle imaginary index of refraction, aspect ratio $Q$, and orientation in space. Effects of the index of refraction on light polarization were shown to be negligible when considering a constant lidar wavelength. Undoubtedly more interesting, $\delta$ is highly sensitive to the aspect ratio $Q$ in the presence of randomly oriented particles. As the slope of $\delta(Q)$ is not always positive, it is not possible to link an observed $\delta$ to a specific $Q$, however a range of possible values for $Q$ can be estimated and crystals can be classified into three shape groups. Low values $\delta<0.25$ are attributed to thin plate-like particles $(Q<0.1)$, while high $\delta>0.5$ are found to be the signature of column-like particles $(Q>1.5)$ and crystals of high complexity such as bullet rosettes. Experimental studies 
have found that particles close to sphericity (early in the particle formation, or through riming process) produce low depolarization, in the same range as plate-like particles, so these shapes will be equivalent in the lidar classification scheme. The last group describes intermediate and irregular particle shapes (with aspect ratios close to unity) that produce average depolarization ratios $(0.25<\delta<0.5)$. It should be stressed that this technique does not aim at retrieving the exact shape of ice crystals in ice clouds, as their infinite variety makes this an unrealistic goal. Instead, the depolarization ratio is used to classify particles in a given cloud area into three distinct groups: plate-like, column-like and irregular shapes. It is important to note that platelike and column-like refer to particles that scatter light respectively like plates (including aggregates of plates) or columns (including aggregate of columns and bullet rosettes). As lidar observations are vertically resolved, the variability of these groups with altitude, temperature, etc. can be estimated.

During the classification, two phenomenons need to be accounted for. First, multiple scattering can greatly modify observations of depolarization ratio ( $\mathrm{Hu}$ et al, 2001), thus a specific Monte-Carlo multiple scattering code has been implemented to simulate this phenomenon in ice clouds of variable composition and optical depths, showing it varies greatly with particle shape (Noel et al, 2002), and therefore the depolarization ranges given for each shape class need to be adjusted for each lidar profile, with respect to the optical depth of the studied cloud. Moreover, Noel et al 2001 showed that horizontally oriented crystals, which are known to occur in midlatitude and high-latitude ice clouds (Platt, 1977; Sassen, 1980; Noel and Sassen 2005), especially at cloud top (Sassen et al. 2003), usually produce high backscattering and almost-zero depolarization ratios $(\delta<0.1)$ in good agreement with experimental studies (Platt et al., 1978). In that case, the depolarization ratio is not sensitive to other parameters anymore, and the shape classification technique used in the present study cannot be applied. Fluid dynamics studies (Jayaweera and Cottis 1969) show that the fall 
attitude of crystals strongly depends on their Reynolds number Re: while particles with low Re (below unity) will adopt a random orientation, crystals with Re above unity will adopt a preferential orientation close to the horizontal plane. Moreover, crystals with $\operatorname{Re}>200$ will tend to oscillate and flutter (Jayaweera and Mason, 1965), with amplitudes dependent on the crystal aspect ratio: planar particles will follow horizontal orientation more closely than complex and irregular shapes (Heymsfield and Kajikawa 1987). For pristine particles such as the planar crystals used in the present classification scheme, Re is typically lower than 200 (Mitchell 1996), and thus such particles would tend to follow a horizontal orientation. Recent studies using polarized observations from the spaceborne radiometer POLDER (Breon and Dubrulle 2004; Noel and Chepfer 2004) have confirmed these findings, showing that oriented crystals can be found in half of ice clouds, in small concentrations however $(0.1$ to $1 \%)$. As the present study assumes random orientation of particles, to remain coherent with radiative transfer studies, occurrences of oriented crystals had to be excluded from the observation dataset. This was achieved by removing cases with very low values of $\delta$, as only a small concentration of oriented crystals is enough to strongly affect the depolarization (Sassen and Benson 2001).

This technique was first applied in Noel et al. (2002) on twelve cases of ground-based lidar observation of $\delta$ in midlatitude ice clouds, with results in good agreement with previous in situ studies (Korolev and Isaac, 1999; Sassen and Benson, 2001). More recently, this technique was applied to observations of ice clouds on top of convective systems in the tropics during the CRYSTAL-FACE campaign (Noel et al. 2004b), highlighting their specific microphysical properties. In this last study, classification results were compared with direct ice particle images observed from collocated in-situ probes, showing a good agreement. The technique was also compared to other remote sensing shape retrieval technique (Chepfer et al. 2005) leading to consistent results. These last validation and comparisons mean the 
classification technique can be trusted with a reasonable level of confidence.

\section{The SIRTA Ice Cloud Dataset}

The 532-nm Lidar Nuages Aerosols (LNA) is operated 5 days a week from 8 AM to 8 PM, except during precipitation, at the SIRTA observatory located at 48.713N, 2.208E (Haeffelin et al., 2005). Its laser beam, pointing at the zenith, leads to a nominal temporal resolution of 10 seconds (200 integrated pulses) and a vertical resolution of 15 meters. The dataset used in this study extends from 2002 to 2004 ; on this period backscattered profiles were analyzed to produce a "cloud mask" with a multi-test algorithm called STRAT (STRucture of the ATmosphere) that identifies the boundary layer, molecular (i.e. particle-free) layers, and particle layers in the troposphere (Morille et al., 2005). Cloud and aerosol layers were detected using a combination of wavelet transform analysis (to detect signal discontinuities at layer boundaries) and backscattered signal thresholding (to remove variations due to noise). Moreover, the LNA produces observations of linear depolarization ratio (Sect. 2), which is calibrated by detecting for each observation period a low-level, cloud-free region and normalizing this region to the standard molecular depolarization ratio of $2.79 \%$ (Young 1980). STRAT separates liquid water clouds from ice clouds using a depolarization threshold of 0.25 . Ice clouds were successfully detected by the lidar on 322 days during the studied period, totaling more than 2400 hours of observation and more than $10^{7}$ points of data. The distribution of ice cloud sightings (i.e. days when the lidar was operated and ice clouds were detected) over an annual cycle is shown in Fig. 1. The maximum number of observations (over 35) occurs in September, following a marked minimum ( 20) in July and August. There is a high number of observations (29 to 34) between January and April, while the smallest number of observations (17 to 20) occurs between November and December. The total days when ice clouds were detected for each season goes from 66 in summer to 94 in spring, with 
79 sightings in winter and 83 in autumn. However, as these numbers come from only 3 years of observation, the statistical variability of ice cloud occurrences from one year to the next is only partially represented. The uncertainty for a month with $N$ ice cloud sightings can be estimated by supposing these follow a Poisson distribution, leading to a standard deviation of $\sqrt{N}$. As it stands, this distribution stems from the natural temporal distribution of ice clouds, but is also influenced by the presence of precipitation (or optically thick low-level clouds) hiding higher ice clouds from the lidar, by non-meteorological causes like technical problems with the lidar, etc. Thus, numbers shown in Fig. 1 are rather meant to ensure that the following analysis will not be biased towards a specific time of the year.

Radiosounding observations used in the present study come from the Meteo-France Trappes station, located $15 \mathrm{~km}$ away from the SIRTA site. Two radiosoundings are available daily, at 00:00 and 12:00 UT. For each data point observed by the lidar (and thus each retrieved shape class) thermodynamic variables like temperature, relative humidity, wind speed and direction were interpolated between radiosoundings, at the time and altitude of lidar observation. As the temperature profile in the upper troposphere does not change significantly without stratosphere/troposphere exchange, this interpolation should not introduce significant bias in temperature ; however, probe measurements of relative humidity can change dramatically on short timescales, depending of the balloon's flight path in the upper troposphere, as it may fly tens of kilometers away across various regions not representative of the area observed by the lidar. Observations of relative humidity should therefore be treated with caution.

The distribution of data points observed in ice clouds as a function of temperature (in bins of $\left.2{ }^{\circ} \mathrm{C}\right)$ is shown in Fig. 2a. An important number of points $(\sim 23 \%)$ show temperatures above $30^{\circ} \mathrm{C}$, however most are observed between $-60^{\circ} \mathrm{C}$ and $-40^{\circ} \mathrm{C}(\sim 43 \%)$, with only a few between $-60^{\circ} \mathrm{C}$ and $-70^{\circ} \mathrm{C}(\sim 12 \%)$. Colder temperatures $\left(<-70^{\circ} \mathrm{C}\right)$ represent $\sim 44000$ points of observations, which is small by comparison (less than $0.5 \%$ ). The distribution of Relative 
Humidity with respect to ice $R H_{I C E}$ for each data point observed by the lidar in a ice cloud is shown in Fig. 2b. The distribution is roughly Gaussian, with a definite trend towards higher humidities and a marked maximum for $85 \%<R H_{I C E}<115 \%$ (more than $65 \%$ of all points). $R H_{I C E}<50 \%$ represents less than $10 \%$ of all points. A distribution centered on high values is consistent with Heymsfield and Miloshevich (1995).

The distribution of data points in ice clouds as a function of wind properties at the altitude of lidar observation is given in Fig. 3: Fig. 3a (top panel) shows the distribution as a function of wind direction (in bins of $10^{\circ}$ ), Fig. $3 \mathrm{~b}$ (right panel) as a function of wind speed (in bins of 2 m.s ${ }^{-1}$ ) and Fig. $3 \mathrm{c}$ (center panel) as a function of both, on a $2 \mathrm{~d}$ histogram using a logarithmic color scale. Half of the data points show a wind speed below $20 \mathrm{~m} \cdot \mathrm{s}^{-1}$, and the main wind group shows speeds below $45 \mathrm{~m} . \mathrm{s}^{-1}$ (Fig. 3b). Considering these low speeds, the related ice clouds should be associated with the presence of atmospheric fronts. Winds in that speed range mostly show directions between $180^{\circ}$ and $360^{\circ}$ (Fig. 3c), meaning they mostly originate from the Atlantic Ocean, which is consistent with the general circulation model. In this domain, four major modes appear (Fig. 3a), centered on $200^{\circ}$ (i.e. SSW), $245^{\circ}$ (i.e. WSW), $295^{\circ}$ (ie WNW) and $340^{\circ}$ (NNW). A distinct separate group appears for speeds in the 60-70 m.s $\mathrm{s}^{-1}$ range (Fig. 3c), typical of jet streams, which can also initiate the formation of ice clouds (Mace et al, 1995). The importance of this group is relatively small, as it does not appear on the linear scales of Fig. 3a and 3b. Nonetheless, there are more than 79400 data points in that speed range - a small number compared to the entire dataset (less than $1 \%$ ), but still significant. Due to the specific ice creation process associated to the presence of jet streams, specific microphysical properties are to be expected. For this group the wind directions are almost essentially between $0^{\circ}$ and $200^{\circ}$, meaning these winds mostly come from the European continent. This disagreement with general circulation means that this relatively small dataset could be dominated by small-scale, local phenomenons, so its representativeness is hard to 
estimate.

\section{Results of the shape classification}

The shape classification technique was applied to the entire dataset of 322 days of ice cloud observations.

\subsection{Example case : June $2^{\text {nd }} 2004$}

The June $2^{\text {nd }} 2004$ case was selected to illustrate the shape classification technique. That day, an ice cloud located between 9 and $11.5 \mathrm{~km}$ was observed by the lidar for 2 hours. Lidar depolarization ratios (Fig. 4a) show high variability, from 0.15 to 0.55 . The associated profiles of temperature, pressure and $R H_{I C E}$ from a radiosounding probe launched at 23:06 UTC are shown in Fig. 4b. Temperatures between $-40^{\circ} \mathrm{C}$ (cloud base, $9 \mathrm{~km}$ ) and $-60^{\circ} \mathrm{C}$ (cloud top, $11.5 \mathrm{~km}$ ), added to high depolarization ratios, confirm the cloud is composed of ice crystals. Values of $R H_{I C E}$ (Fig. $4 \mathrm{~b}$ ) are stable (50\%-55\%) in the cloud altitude range.

Fig. $4 \mathrm{c}$ shows the results of the ice particle shape classification. Blue areas are dominated by plate-like particles; yellow denotes irregular crystal shapes ( unity aspect ratios); and red areas are dominated by column-like crystal shapes. The cloud originates at high altitude (10.5 to $11.5 \mathrm{~km}$ at $20: 30 \mathrm{UTC}$ ), showing a wide range of depolarization ratios (Fig. 4a) that suggests a mixture of particle shapes (Fig. 4c) - plates, columns and irregulars. Between 21:00 and 21:15 UTC, the layer extends down to $9.5 \mathrm{~km}$, with high depolarization ratios $(\delta>0.45)$ suggesting column-like particles dominate the cloud (red, Fig. 4c). From then on, the cloud layer stays stable between 9 and $11 \mathrm{~km}$, while the depolarization ratio decreases $(0.2<\delta<0.4)$. This suggests crystals undergo shape modifications due to size increase, by vapor deposition or secondary crystal formation mechanisms (aggregation/fragmentation from sedimentation or movement inside the cloud), leading eventually to dominance by irregular shapes (yellow, Fig. 4c). Areas immediately outside the cloud layer (9 and $11.5 \mathrm{~km})$ show low 
depolarization ratios (Fig. 4a) - these are classified as plate-like particles, but could also be explained by evaporation at cloud boundaries, leading to a general rounding of particles.

\subsection{Results on the entire dataset}

The annual distribution of shape class relative concentrations does not reveal any remarkable trend. Between January and April, clouds are marked by a lot of irregular shapes (up to 55\% in March) and only a few plate-like particles. From May to December, plate-like and irregular shapes appear in similar concentrations. Concentration of column-like shapes is usually low, reaching a minimum of $16 \%$ in May. However, as measurements are not evenly distributed over time (Sect. 3), it is unclear whether these numbers are representative of mid-latitude ice clouds.

More significantly, the shape of ice particles appears highly sensitive to temperature (Fig. 5) : for temperatures above $-20^{\circ} \mathrm{C}$, plate-like particles are predominant $(50 \%-70 \%)$, followed by irregular particles (25\%-40\%), and a minority of column-like particles (less than $10 \%)$. As altitude increases and temperatures drop, the importance of plate-like particles decreases, with a simultaneous increase in the two other classes. A threshold is reached at $-50^{\circ} \mathrm{C}$, where the relative concentration of irregular shapes ( unity aspect ratio) reaches its maximum $(\sim 50 \%$ of all particles), while at the same time column-like particles become more frequent than platelike particles. For colder temperatures (below $-50^{\circ} \mathrm{C}$ ), the concentration of irregular shapes and plate-like particles decreases to fall below $20 \%$ at $-75^{\circ} \mathrm{C}$, while the proportion of columnlike particles goes on increasing to reach its maximum (over $70 \%$ ) at $-75^{\circ} \mathrm{C}$. A pronounced change seems to be occurring for even colder temperatures (below $-75^{\circ} \mathrm{C}$ ) with a sharp fall in column-like concentrations and a sharp increase in plate-like particles.

The shape class relative concentrations are shown in Fig. 6 as a function of relative humidity with respect to ice $R H_{I C E}$. Low humidity is dominated equally by plate-like and irregular 
shapes (45\%-50\%), followed by less than $25 \%$ of column-like particles. At higher humidity, the proportion of plate-like shapes decreases while column-like particles increase. This behavior stops at $R H_{I C E}=100 \%$ (the most frequent value, Fig. 2b), with plate-like particles below $30 \%$, and column-like reaching almost $30 \%$. For $R H_{I C E}>100 \%$ plate-like concentrations increase (reaching 55\% around $R H_{I C E}=140 \%$ ) and column-like concentrations fall (below $10 \%$ at $R H_{I C E}=150 \%$ ). Such high values of $R H_{I C E}$ may suggest the presence of mixed-phase clouds. The concentration of irregular shapes stays between 35 and $50 \%$ overall. A sharp change can be observed for $R H_{I C E}>160 \%$ : plate-like concentrations fall below $25 \%$ while the irregular particles rise above $60 \%$. However there are less than 500 data points in this range (i.e. less than $0.1 \%$ ) so the representativity of this behavior is unclear.

The shape class relative concentrations are shown in Fig. 7 as a function of wind speed. Winds below $20 \mathrm{~m} \cdot \mathrm{s}^{-1}$ show more than $40 \%$ of plate-like, $30-40 \%$ of irregular and $20-30 \%$ of column-like particles. Distributions are stable from 20 to $50 \mathrm{~m} . \mathrm{s}^{-1}$, with similar concentrations of column-like and irregular particles (30-45\%) and less plate-like particles (15-20\%). At 60 $\mathrm{m} . \mathrm{s}^{-1}$, the relative concentration of column-like particles jumps sharply above $55 \%$, while irregular and plate-like shape concentrations fall respectively to less than $30 \%$ and $15 \%$.

The shape relative concentrations are shown in Fig. 8 as a function of temperature, for the four wind directions identified in Sect. 3 (Fig 3c). Above $-20^{\circ} \mathrm{C}$, shape class concentrations in all directions follow the trend identified in Fig. 5: a majority of plate-like shapes, followed by irregular and finally column-like shapes. Irregular shapes also follows the same trend: concentrations are low for warm $\left(>-20^{\circ} \mathrm{C}\right)$ and cold $\left(<-60^{\circ} \mathrm{C}\right)$ temperatures, and high between $-45^{\circ} \mathrm{C}$ and $-55^{\circ} \mathrm{C}$. Winds between $175^{\circ}$ and $225^{\circ}$ show high concentrations of irregular shapes (above $60 \%$ ) for temperatures below $-60^{\circ} \mathrm{C}$, at the expense of the two other shape classes (below 30\%). When compared with Fig. 5, plate-like and column-like particles compensate for each other : lower-than-average concentrations of column-like particles are balanced by 
high concentrations of plate-like particles, and vice versa. Winds between $175^{\circ}$ and $220^{\circ}$ show low concentrations of column-like particles and higher-than-average concentrations of plate-like and irregular shapes until $-70^{\circ} \mathrm{C}$, where the situation is reversed. For winds between $220^{\circ}$ and $275^{\circ}$, plate-like and column-like concentrations are symmetric and opposite around $45^{\circ} \mathrm{C}$, where they both reach $\sim 25 \%$. Winds between $275^{\circ}$ and $315^{\circ}$ show more column-like (35-50\%) than plate-like particles (below 25\%). Winds between $315^{\circ}$ and $360^{\circ}$ show very little column-like particles (less than $5 \%$ ) at temperatures above $-30^{\circ} \mathrm{C}$, but a lot of plate-like particles (more than $50 \%$ ). Between $-35^{\circ} \mathrm{C}$ and $-30^{\circ} \mathrm{C}$ irregular shapes represent $70 \%$, but their number decreases below $-40^{\circ} \mathrm{C}$ while column-like particles become dominant $(5 \%$ at $30^{\circ} \mathrm{C}, 55 \%$ at $-45^{\circ} \mathrm{C}$ ). It should also be noted that below $-75^{\circ} \mathrm{C}$ winds from the West (Fig $8 \mathrm{~b}$ and c) show a sharp increase in plate-like and a decrease in column-like particles that is not seen in winds from the South (Fig. 8a) or North (Fig. 8d).

The shape class relative concentrations are shown in Fig. 9 as a function of wind direction. For speeds below $40 \mathrm{~m} \cdot \mathrm{s}^{-1}$ (Fig. 9a), winds between $180^{\circ}$ and $360^{\circ}$ (from the Atlantic Ocean) show similar concentrations for the three classes (30-35\%) ; winds between $0^{\circ}$ and $180^{\circ}$ (from the European continent) show more than $60 \%$ of plate-like particles and very little columnlike particles $\left(10 \%\right.$ between $100^{\circ}$ and $\left.150^{\circ}\right)$. Winds between $45^{\circ}$ and $55^{\circ}$ show an increase in column-like (more than 25\%) and a decrease in plate-like particles. High-speed winds (Fig. 9b) show between $0^{\circ}$ and $180^{\circ}$ more than $60 \%$ of column-like, followed by irregular (3045\%) and finally plate-like shapes (less than 10\%). As these winds from Europe are mostly associated with jet streams (Fig. 3c), this is coherent with the wind speed influence evidenced by Fig. 8. Winds from the Atlantic show little column-like particles (below 20\%) in the $180^{\circ}-200^{\circ}$ range and the $330^{\circ}-360^{\circ}$ range, while concentrations increase for the two other shapes. At $275^{\circ}$, column concentrations reach $90 \%$ while the other shapes disappear however, there is little observation for high-speed winds between $180^{\circ}$ and $360^{\circ}$ (Fig. 3c), so 
it is unclear if these observations are representative of actual ice clouds.

In summary, the dependence of crystal shape relative concentrations with temperature (Fig. 5) and relative humidity (Fig. 6) are the most clearly marked, and should be the easiest to model. However, as was previously noted, it is impossible to assess with confidence that relative humidity observations from radiosoundings are representative of ice clouds probed by the lidar. Conversely, temperature measurements can be relied upon, and the evolution of each shape class relative concentration with temperature seems smooth enough to propose a parametrization based on it. Parameters for second-order polynomial regressions, of the form $C_{i}=a_{i} T^{2}+b_{i} T+c_{i}$, are given in Table 1, with the associated curves plotted in dashed lines in Fig. 5. The concentrations variation with temperature is well reproduced.

\section{Discussion and conclusion}

A technique for classifying ice cloud areas into three major shape groups (plate-like, irregular or column-like shapes) based on observations of lidar depolarization ratio (Sect. 2) has been applied to three years of ice clouds observations over the SIRTA ground-based site (Sect. 3). Results of the shape classification (Sect. 4) have been compared with atmospheric variables like temperature, relative humidity, wind speed and direction. A strong correlation of particle shape with most atmospheric variables is found.

The correlation of retrieved particle shapes with relative humidity (Fig. 6) shows that columnlike particles are rare for low $(<20 \%)$ or high $(>120 \%)$ values of $R H_{I C E}$. High values $(110 \%<$ $R H_{I C E}<150 \%$ ) are strongly dominated by plate-like particles, while the most frequent values $\left(80 \%<R H_{I C E}<120 \%\right)$ show a balanced mix of plate-like, irregular and column-like shapes (30-45\% for each shape). However, as relative humidity measurements from probes are difficult at the high altitude of ice clouds due to the high spatial variability of this parameter, more detailed observations (e.g. from coincident in situ probes, Heymsfield and Miloshevitch 
1995) are therefore needed to confirm these results.

Correlation of particle shapes with wind direction (Fig. 8 and 9) shows that different composition of air masses coming from different sources have a strong impact on the microphysical properties of the created ice cloud: winds from the East $\left(0-180^{\circ}\right)$ show a specific composition (low concentration of column-like particles, dominance of plate-like particles for low wind speeds and irregular for high wind speeds), different from the one of winds from the West (column-like particles dominate, whatever the wind speed). The correlation of retrieved particle shapes with wind speed (Fig. 8) shows that higher wind speeds lead to more column-like particles, with a specific shape distribution for wind speeds $\sim 60 \mathrm{~m} . \mathrm{s}^{-1}$. This suggests that ice clouds created in the presence of jet streams are dominated by column-like particles (more than $50 \%$ ) or particles of high complexity such as bullet rosettes (Heymsfield et al, 2002b), followed by lower concentrations of irregular shapes $(\sim 30 \%)$ and a marked minority of plate-like shapes $(\sim 10 \%)$. As jet streams are generally present at coldest temperatures, close to the tropopause, this is consistent with the temperature distribution of shape classes (Fig. 5), which shows a majority of columns in such temperature ranges. column-like shapes are however not restricted to jet-created ice clouds. The distribution of wind speeds (Fig. 3) shows that high wind speeds are poorly represented in ice clouds observed over the SIRTA (less than $1 \%$ of the entire population of ice clouds). This might suggests that ice cloud creation by jet streams is of limited importance at this location, but it might also be explained by correlation of jet streams with lower, optically thick cloud systems that would hide the ice cloud to the lidar. Such a correlation could be coincidental, or due to some unexplained relationship between low-level cloud systems and jet streams. Jetcreated ice clouds would then be under-represented in the current dataset.

The correlation between particle shapes and temperature is maybe the most pronounced one (Fig. 5), with a clear and successive dominance by plate-like, irregular and column-like 
shapes as temperature decreases. This evolution is due to the different physical processes dominating crystal formation at different temperatures (Sassen et al 1989), which are however still unclear at this point. Concentration of plate-like particles is higher in warm ice clouds (above $-20^{\circ} \mathrm{C}$ ) and decreases with colder temperatures while concentration of irregular shapes slowly increases. This mixture of plate-like and irregular shapes is coherent with the temperature range, which is identified with the plate and dendrite growth regime (Pruppacher and Klett 1997). The concentration of column-like particle slowly increases with decreasing temperatures, to completely dominate the particle population at coldest temperatures (below $70^{\circ} \mathrm{C}$ ), where the more pristine and geometric particles are to be expected. This trend, coherent with results from Hallett (1987), can be explained either by in-situ formation of pristine and geometric particles at extremely cold temperatures, or by general changes in the shape of crystals as they move from warmer to colder temperatures (Sassen and Benson, 2001). Relative concentration of irregular shapes is low at extreme temperatures (both coldest and warmest), but dominates the ice particles population at midlevel temperatures $\left(-50^{\circ} \mathrm{C}\right.$ to $40^{\circ} \mathrm{C}$ ). For the coldest temperatures (below $-75^{\circ} \mathrm{C}$ ), a sharp increase in the concentration of plate-like particles is observed, coupled to a decrease in column-like particle concentrations. This last change might just be a local effect due to the small number of data points in this temperature range (Fig. 2a). However, the possibility that these observations are significant of extremely cold ice cloud that would exhibit specific microphysical properties (Heymsfield, 1986) should not be excluded. The evolution of shape class relative concentrations with temperature is reproduced quite well by $2^{\text {nd }}$ order polynomial regressions. As the crystal shape influences its fall speed in the cloud (Heymsfield and Iaquinta, 2000), these relative concentrations could also help refine the parameterization of ice particle sedimentation speeds as a function of temperature or latitude, once a more comprehensive lidar dataset is available. Even if the considered dataset extends over a large time period, the observations remain local, 
and it is unclear whether they are actually representative of the entire population of midlatitude ice clouds. It can be noted however that these results are consistent with previous studies using lidar observations, such as the 6-years midlatitude ice cloud climatology presented by Sassen and Benson (2001), which shows a regular increase in depolarization ratio with falling temperatures (from $\delta=0.25$ at $-17.5^{\circ} \mathrm{C}$ to $\delta=0.45$ at $-77.5^{\circ} \mathrm{C}$ ), and concludes to high concentrations of plate-like particles for temperatures above $-20^{\circ} \mathrm{C}$. For temperatures below $-55^{\circ} \mathrm{C}$, ice crystal observations from in-situ airborne PMS probes stress the high frequency of column-like particles (Heymsfield and Platt 1984). Other in-situ observations in high- and mid-latitude ice clouds (Korolev and Hallett 2000) also suggest high concentrations of irregular shapes, with coldest temperatures dominated by columns. Comparison of the present results with passive satellite retrievals is difficult due to the unknown vertical integrating distance of such studies; however, analysis of satellite observations using the POLDER radiometer (Chepfer et al., 2001) have highlighted the strong variability of dominant crystal shape with latitude.

In that respect, it is interesting to compare the present retrievals with results of the same analysis applied to 3 days of tropical convective ice clouds (Noel et al. 2004), observed with the airborne and downward-looking Cloud Physics Lidar (CPL, McGill et al 2002) during the CRYSTAL-FACE campaign (Jensen et al., 2004), that showed a constant minority of column-like particles (less than 10\%) coupled with a quasi-linear decrease of the concentration of plate-like particles (from $65 \%$ at $-20^{\circ} \mathrm{C}$ to $10 \%$ at $-70^{\circ} \mathrm{C}$ ) and a simultaneous increase in irregular shapes (from $30 \%$ at $-20^{\circ} \mathrm{C}$ to more than $80 \%$ at $-70^{\circ} \mathrm{C}$ ). Tropical convective ice clouds thus showed dominance of plate-like particles at warmest temperatures (above $-35^{\circ} \mathrm{C}$, similar to midlatitude ice clouds), while irregular shapes dominated all temperatures below $-35^{\circ} \mathrm{C}$, with no trace of the regular increase in columns observed in midlatitude ice clouds (Fig. 6). 
These strong differences between tropical and midlatitude ice clouds remind us that different formation processes lead to different microphysical properties, which in turn lead to strong differences in the clouds radiative impact (Takano and Liou, 1989). These differences need to be taken into account in numerical models of climate prediction. The large observation dataset of the present study (three years of observations) ensures that the suggested parameterizations may be considered representative of midlatitude ice clouds with some confidence. Of course, this assumes that ice clouds observed over the SIRTA ground-based sites are representative of midlatitude ice clouds - in order to validate that hypothesis, and make sure that no local synoptic process due to the proximity to the Atlantic Ocean is at work, more midlatitude ice clouds from different locations should be studied. Similar studies in tropical convective ice clouds suggest that similar parameterizations could be done at other latitudes, however there too more observations are be required to get representative results. Unfortunately, lidar studies of tropical convective systems are extremely difficult due to their high optical thickness that blocks lidar penetration from the ground. In this context, the spacebased Cloud Aerosol Lidar and Infrared Pathfinder Satellite Observations mission (CALIPSO, Winker et al. 2003) will send a 532-nm lidar into orbit in July 2005 to observe ice cloud properties from above, even on top of optically thick cloud systems, all around the globe. The shape classification technique featured in the present study has been selected by NASA to be applied on an operational basis on the linear depolarization ratios observed from the CALIPSO lidar, and the retrieved shape class relative concentrations will be integrated into the level 2 products available as soon as January 2006. At this point, it is important to stress out the limitations of the classification scheme: only three shape categories can be considered, which reflects only partially the infinite variety of particles found in ice clouds. More research and simulations are therefore needed to refine this classification Moreover, the impact of orientation and shape on depolarization ratios is still not fully understood, thus the 
interpretation of these results could change based on new advances in light scattering models or laboratory experiment. In the present day, however, this kind of study is one of the few that can provide large-scale retrieval of information about particle shape, leading to global maps of particle shape class concentrations and giving an invaluable insight into the microphysical properties of ice clouds, whatever the latitude. Moreover, results of this classification will be used operationally in algorithms of particle size retrieval using observations from the threechannel Infrared Imager (IIR) radiometer, also present on the CALIPSO platform (Chiriaco et al. 2005). These observations will provide a unique point of view on the microphysical properties of ice clouds that will allow studying the link between thermodynamic variables and the particle shape associated to various ice cloud formations types in different regions of the globe.

Acknowledgments : This research was supported in part by the NASA Langley Research Center under contract NAS1-02058. The authors would like to thank the SIRTA technical and computer staff (Christophe Boitel, Florian Lapouge, Dr. Christophe Pietras, Bernard Romand) for taking the observations and making the dataset easily accessible. The authors would like to thank Dave M. Winker for his support. 


\section{References}

- Breon F. M., B. Dubrulle 2004 : Horizontally oriented plates in clouds, J. Atmos. Sci. 61, 2888-2898.

- Cess, R.D., G.L. Potter, J.P. Blanchet, G.J. Boer, A.D. Del Genio, M. Deque, V. Dymnikov, V. Galin, W.L. Gates, S.J. Ghan, J.T. Kiehl, A.A. Lacis, H. Le Treut, Z.X. Li, X.-Z. Liang, B.J. McAvaney, V.P. Meleshko, J.F.B. Mitchell, J.-J. Morcrette, D.A. Randall, L. Rikus, E. Roeckner, J.F. Royer, U. Schlese, D.A. Sheinin, A. Slingo, A.P. Sokolov, K.E. Taylor, W.M. Washington, R.T. Wetherald, I. Yagai, and M.-H. Zhang 1990 : Intercomparison and interpretation of climate feedback processes in 19 atmospheric general circulation models, J. Geophys. Res., 95, 16,601-16,615.

- Cess, R.D., M.H. Zhang, W.J. Ingram, G.L. Potter, V. Alekseev, H.W. Barker, E. Cohen-Solal, R.A. Colman, D.A. Dazlich, A.D. Del Genio, M.R. Dix, V. Dymnikov, M. Esch, L.D. Fowler, J.R. Fraser, V. Galin, W.L. Gates, J.J. Hack, J.T. Kiehl, H. Le Treut, K.K.-W. Lo, B.J. McAvaney, V.P. Meleshko, J.-J. Morcrette, D.A. Randall, E. Roeckner, J.-F. Royer, M.E. Schelsinger, P.V. Sporyshev, B. Timbal, E.M. Volodin, K.E. Taylor, W. Wang, and R.T. Wetherald 1996 : Cloud feedback in atmospheric general circulation models: An update. J. of Geophys. Res. 101, 12791-12794.

- Chen Wei-Nai, Chih-Wei Chiang, and Jan-Bai Nee 2002 : Lidar ratio and depolarization ratio for cirrus clouds, Applied Optics, 40, 6470-6476.

- Chepfer H., G. Brogniez, and Y. Fouquart, 1998 : Cirrus clouds microphysical properties deduced from POLDER observations, J. Quant. Spectr. and Rad. Transfer, 60, 375-390.

- Chepfer H., G. Brogniez, P. Goloub, F. M. Breon and P. H. Flamant, 1999 : Observations of horizontally oriented ice crystals in cirrus clouds with POLDER1/ADEOS-1. J. Quant. Spectr. And Rad. Trans. 63 , 521-543 
- Chepfer H., P. Goloub, J. Riedi, J. De Haan, J. Hovenier, P. H. Flamant, 2001 : Ice crystal shapes in cirrus clouds derived from POLDER-1/ADEOS-1, J. Geophys. Res., 106, $7955-7966$

- Chepfer H., V. Noel, P. Minnis, D. Baumgardner, G. Raga, L. Nguyen, Mc. Ghill and P. Yang, 2005 : Ice crystal habit of tropical ice clouds during Crystal-face : comparisons of two remote sensing techniques results with in-situ, in press, $J$. Geophys. Res.

- Chiriaco M., H. Chepfer, V. Noel, A. Delaval, M. Haeffelin, P. Dubuisson, P. Yang 2004 : Improving Retrievals of Cirrus Cloud Particle Size Coupling Lidar and ThreeChannel Radiometric Techniques. Mon. Wea. Rev. 132, 1684-1700.

- Chiriaco M., H. Chepfer, P. Minnis, M. Haeffelin, S. Platnick, D. Baumgardner, P. Dubuisson, M. McGill, V. Noël, J. Pelon, D. Spangenberg, S. Sun-Mack, G. Wind, 2005 : Comparison of CALIPSO-like, LaRC and MODIS Retrievals of Ice Cloud Properties over SIRTA in France and Florida during CRYSTAL-FACE, accepted for publication in the J. of Appl. Met.

- Cox S. K., D. S. MacDougal, D. A. Randall, and R. A. Schiffer, 1990 : "FIRE, the first ISCCP regional experiment,” Bull. Am. Meteorol. Soc. 68, 112-118.

- Francis P. N., A. Jones, R. W. Saunders, K. P. Shine, A. Slingo, and Z. Sun, 1994 : An observational and theorical study of the radiative properties of cirrus: Some results from ICE'89. Q. J. R. Meteorol. Soc. 120, 809-848

- Garrett T. J., H. Gerber, D. G. Baumgardner, C. H. Twohy, and E. M. Weinstock, 2003 : Small, highly reflective ice crystals in low-latitude cirrus. Geophys. Res. Lett. 30, doi:10.1029/2003GL018153.

- Goldfarb L., P. Keckhut M.-L. Chanin and A. Hauchecorne, 2001 : Cirrus climatological results from lidar measurements at OHP (44N, 6E). Geophys. Res. Let. 
$28,1687-1690$

- Haeffelin, M., L. Barthès, O. Bock, C. Boitel, S. Bony, D. Bouniol, H. Chepfer, M. Chiriaco, J. Cuesta, J. Delanoë, P. Drobinski, J-L. Dufresne, C. Flamant, M. Grall, A. Hodzic, F. Hourdin, F. Lapouge, Y. Lemaître, A. Mathieu, Y. Morille, C. Naud, V. Noël, B. O’Hirok, J. Pelon, C. Pietras, A. Protat, B. Romand, G. Scialom, R. Vautard, 2005 : SIRTA, a ground-based atmospheric observatory for cloud and aerosol research. Annales Geophysicae, 23, pp 253-275.

- J. Hallett 1987 : Faceted snow crystals. J. Opt. Soc. Am., 4, 581-588.

- Heymsfield, A. and C. M. R. Platt 1984 : A parametrization of the particle size spectrum of ice clouds in terms of the ambient temperature and the ice water content $J$. Of Atmos. Sci., 41 , 846-855.

- Heymsfield, A. 1986 : Ice particles observed in a cirriform cloud at -83C and implications for polar stratospheric clouds. J. of Atmos.Sci. 43, 851-855

- Heymsfield A. J. and M. Kajikawa, 1987 : An improved approach to calculating terminal velocities of plate-like crystals and graupels. J. Atmos. Sci. 44 (7), 10881099.

- Heymsfield A. J. and L. M. Miloshevich, 1995 : Relative humidity and temperature influences on cirrus formation and evolution: Observations from wave clouds and FIRE-II. J. Atmos. Sci. 52 , 4302-4326.

- Heymsfield A. J. and J. Iaquinta 2000 : Cirrus Crystal terminal velocity. J. Atmos. Sci. $57,916-938$

- Heymsfield A. J., Aaron Bansemer, Paul R. Field, Stephen L. Durden, Jeffrey L. Stith, James E. Dye, William Hall, Cedric A. Grainger 2002 : Observations and Parameterizations of Particle Size Distributions in Deep Tropical Cirrus and Stratiform Precipitating Clouds: Results from In Situ Observations in TRMM Field 
Campaigns.J. Atmos. Sci. 59, 3457-3491

- Heymsfield A. J., S. Lewis, A. Bansemer, J. Iaquinta, L. M. Miloshevich, M. Kajikawa, C. Twohy and M. R. Poellot. 2002 : A General Approach for Deriving the Properties of Cirrus and Stratiform Ice Cloud Particles. J. Atmos. Sci. 59 (1), 3-29.

- Hu, Y. X., D. Winker, P. Yang, B. Baum, L. Poole, and L. Vann, 2001 : Identification of cloud phase from PICASSO-CENA lidar depolarization: A multiple scattering sensitivity study. J. Quant. Spectrosc. Radiat. Transfer 70, $569-579$.

- Jayaweera, K. O. L. F. and R. E. Cottis, 1969 : Fall velocities of plate-like and columnar ice crystals. Quart. J. R. Met. Soc. 95, 703-709.

- Jayaweera K. O. L. F. and B. J. Mason, 1965 : The behaviour of freely falling cylinders and cones in a viscous fluid. J. Fluid Mech. 22 (4), 709-720.

- Jensen E. J., D. Starr and O. B. Toon 2004 : Mission investigates tropical cirrus clouds. EOS, 85 , 45-50.

- Korolev A.V. and G. A. Isaac 1999 : Ice particle habits in Arctic clouds. Geophys. Res. Let. 26, 1299-1302

- Korolev G. A. and I. J. Hallett, 2000 : Ice particle habits in stratiform clouds, Q. J. R. Meteorol. Soc., 126, 2873- 2902.

- Liou K. N., 1986 : Influence of cirrus clouds on weather and climate processes: A global perspective, Mon. Weather Rev., 114, 1167-1199.

- Mace G. G., D. C. O'Starr, T. P. Ackerman and P. Minnis, 1995 : Examination of coupling between an upper tropospheric cloud system and synoptic scale dynamics diagnosed from wind profiler and radiosonde data. J. Atmos. Sci. 52, 4094-4127.

- Masuda K., H. Ishimoto, and T. Takashima, 2002 : Retrieval of cirrus optical thickness and ice-shape information using total and polarized reflectance from satellite measurements. J. of Quant. Spec. and Rad. Trans., 75 , 39-51 
- McGill M. J., D. L. Hlavka, W. D. Hart, J. D. Spinhirne, V. S. Scott and B. Schmid 2002 : The Cloud Physics Lidar: Instrument description and initial measurement results. Applied Optics 41, 3725-3734

- Mishchenko M. I., W. B. Rossow, A. Macke and A. Lacis, 1996 : Sensitivity of cirrus cloud albedo, bidirectional reflectance and optical thickness retrieval accuracy to ice particle shape. J. Of Geophys. Rev., 101, 16973-16985

- Mitchell D. L., 1996 : Use of Mass- and Area-Dimensional Power Laws for Determining Precipitation Particle Terminal Velocities. J. Atmos. Sci. 53 (12), 17101723.

- Morille Y., M. Haeffelin, P. Drobinski, J. Pelon, 2005 : STRAT : STRucture of the ATmosphere retrieved from single channel lidar data. Submitted to the J. Of Atmos. And Ocean. Tech.

- Noel V., H. Chepfer, G. Ledanois, and P. H. Flamant, 2001 : Computation of a single scattering matrix for nonspherical particles randomly or horizontally oriented in space. Appl. Opt., 40, 4365- 4375.

- Noel V., H. Chepfer, G. Ledanois, A. Delaval, and P. H. Flamant, 2002 : Classification of particle shape ratios in cirrus clouds based on the lidar depolarization ratio. Appl. Opt., 41, 4245- 4257.

- Noel V. and H. Chepfer 2004 : Study of Ice Crystal Orientation in Cirrus Clouds Based on Satellite Polarized Radiance Measurements, J. of Atmos. Sci., 61, 20732081 .

- Noel V., D. M. Winker, M. McGill and P. Lawson, 2004 : Classification of particle shapes from lidar depolarization ratio in convective ice clouds compared to in situ observations during CRYSTAL-FACE, J. Geophys. Res., 109, D24213.

- Noel V. and K. Sassen 2005 : Study of Planar Ice Crystal Orientations in Ice Clouds 
from Scanning Polarization Lidar Observations. Accepted for publication in the $J$. Of Appl. Met.

- Platt C., 1973 : Lidar and radiometric observations of cirrus clouds, J. Atmos. Sci., 30, $1191-1204$.

- Platt C. M. R., N. L. Abshire, and G. T. McNice, 1978 : Some microphysical properties of an ice cloud from lidar observations of horizontally oriented crystals, $J$. Appl. Meteorol., 17, 1220-1224.

- Rolland P., K. N. Liou, M. D. King, S. C. Tsay, and G. M. McFarquhar, 2000 : Remote sensing of optical and microphysical properties of cirrus clouds using modis channels. J. Geophys. Res. 105, 11721-11738

- Sassen K., 1977 : Ice crystal habit discrimination with the optical backscatter depolarization technique. J. Of App. Met., 16, 425-431

- Sassen, K., 1980 : Remote sensing of planar ice crystals fall attitude, J. Meteorol. Soc. Japan, 58, 422- 433 .

- Sassen K., M. Griffin, and G. C. Dodd, 1989 : Optical scattering and microphysical properties of subvisual cirrus clouds and climatic implications. J. Of Appl. Met., 28, $91-98$

- Sassen K., 1991 : The polarization lidar technique for cloud research : a review and current assessment. Bull. Am. Meteorol. Soc., 71 , 1848-1866

- Sassen, K. and J. R. Campbell, 2001 : A midlatitude cirrus cloud climatology from the Facility for Atmospheric Remote Sensing. Part I : macrophysical and synoptic properties. J. Of Atmos. Sci., 58 , 481-496.

- Sassen, K. and S. Benson, 2001 : A midlatitude cirrus cloud climatology from the facility for atmospheric remote sensing. Part II: Microphysical properties derived from lidar depolarisation, J. Of Atmos. Sci., 58, 2103-2111. 
- Sassen K., P. W. Arnott, D. O'C.Starr, G. G. Mace, Z. Wang, M. R. Poellot, 2003 : Midlatitude Cirrus Clouds Derived from Hurricane Nora: A Case Study with Implications for Ice Crystal Nucleation and Shape. Journal of the Atmospheric Sciences 60, 873-891.

- Sassen K., K. N. Liou, Y. Takano, V. I. Khvorostyanov 2003 : Diurnal effects in the composition of cirrus clouds. Geophy. Res. Let. 30, 46.

- Sauvage L., H. Chepfer, V. Trouillet, P. H. Flamant, G. Brogniez, and J. Pelon, 1999 : Remote sensing of cirrus radiative parameters during EUCREX'94. Part 1: Observations and analyses at the regional scale, Mon. Weather Rev. 127, 486- 503

- Stephens G. L., S.-C. Tsay, P. W. Stackhouse and P. J. Flatau 1990 : The relevance of the microphysical and radiative properties of cirrus clouds to climate and climate feedback. J. Of Atmos. Sci., 47, 1742-1753

- Sun Z. and K. P. Shine 1995 : Parameterization of ice cloud radiative properties and its application to the potential climatic importance of mixed-phased clouds. $J$. Of Climate 8 , 1874-1888.

- Takano Y. and K. N. Liou 1989 : Solar Radiative transfer in Cirrus Clouds. Part 1 : Single-Scattering and Optical Properties of Hexagonal Ice Crystals. J. Atmos. Sci. 46, $3-18$.

- Wang P., P. Minnis, M. P. McCormick, G. S. Kent, K. M. Skeens, 1996 : A 6-year climatology of cloud occurrence frequency from SAGE II Observations (1985-1990). J. Of Geophys. Res. 101, 407-429.

- Winker D. M., J. Pelon, and M. P. McCormick, 2003 : The CALIPSO mission: Spaceborne lidar for observation of aerosols and clouds, Proc. SPIE Int. Soc. Opt. Eng., 4893, 1-11.

- Yang, P., B. C. Gao, B. A. Baum, W. J. Wiscombe, Y. X. Hu, S. L. Nasiri, P. F. 
Soulen, A. J. Heymsfield G., M. McFarquhar, L. M. Miloshevich., 2001 : Sensitivity of cirrus bidirectional reflectance to vertical imhomogeneous of ice crystals habits and size distribution for two Moderate-Resolution Imaging Spectroradiometer (MODIS), J. Geophys. Res., 106, 17,267-17,291.

- Young A. T., 1980 : Revised depolarization corrections for atmospheric extinction. Appl. Opt. 19, 3427-3428. 


\section{Table Captions}

Table 1 : Parameters for $2^{\text {nd }}$ order polynomial regression of each shape group $i$ relative concentration as a function of temperature : $C_{i}=a_{i} T^{2}+b_{i} T+c_{i}$ 


\begin{tabular}{|l|c|c|c|}
\hline \multicolumn{1}{|c|}{ Shape Class } & $a$ & $b$ & $c$ \\
\hline plate-like (class 1) & 0.0194 & 2.356 & 88.46 \\
\hline irregular (class 2) & -0.0269 & -2.149 & 5.71 \\
\hline Columns (class 3) & 0.0075 & -0.206 & 5.82 \\
\hline
\end{tabular}

Table 1 : Parameters for $2^{\text {nd }}$ order polynomial regression of each shape group $i$ relative concentration as a function of temperature : $C_{i}=a_{i} T^{2}+b_{i} T+c_{i}$ 


\section{Figures Captions}

Fig. 1 : Distribution of ice cloud observations over an annual cycle during the 2002-2004 period.

Fig 2 : Distribution of lidar data points observed in ice clouds as a function of (a) temperature and (b) relative humidity with respect to ice.

Fig. 3 : (a) Distribution of lidar data points observed in ice clouds as a function of wind direction (top panel). (b) : Same as (a), as a function of wind speed (right panel). (c) same as $\mathrm{a}$, as a function of wind direction (x axis) and speed (y axis), in logarithmic color scale (center panel).

Fig 4 (a) : Observations of lidar depolarization ratio as a function of time and altitude for the June $2^{\text {nd }} 2004$ case (top panel). (b) Profiles of temperature $\left({ }^{\circ} \mathrm{C}\right)$, pressure (hPa) and relative humidity (\%) as a function of altitude, from Trappes radiosoundings at 23:06 (bottom panel). (c) : Results of the shape classification technique as a function of time and altitude for the July $2^{\text {nd }} 2004$ case.

Fig. 5 : Distribution of shape class relative concentrations as a function of atmospheric temperature, with $2^{\text {nd }}$-order polynomial regression (dashed lines).

Fig. 6 : Distribution of shape class relative concentrations as a function of atmospheric relative humidity with respect to ice.

Fig. 7 : Distribution of shape class relative concentrations as a function of wind speed. Fig. 8 : Distribution of shape class relative concentrations as a function of temperature, for wind directions (a) between $175^{\circ}$ and $225^{\circ}$ (SSW), (b) between $220^{\circ}$ and $275^{\circ}$ (WSW), (c) between $275^{\circ}$ and $315^{\circ}(\mathrm{WNW})$ and (d) between $315^{\circ}$ and $360^{\circ}(\mathrm{NNW})$.

Fig. 9 : Distribution of shape class relative concentrations as a function of wind direction, for wind speeds (a) below $45 \mathrm{~m} \cdot \mathrm{s}^{-1}$ and (b) above $45 \mathrm{~m} \cdot \mathrm{s}^{-1}$. 


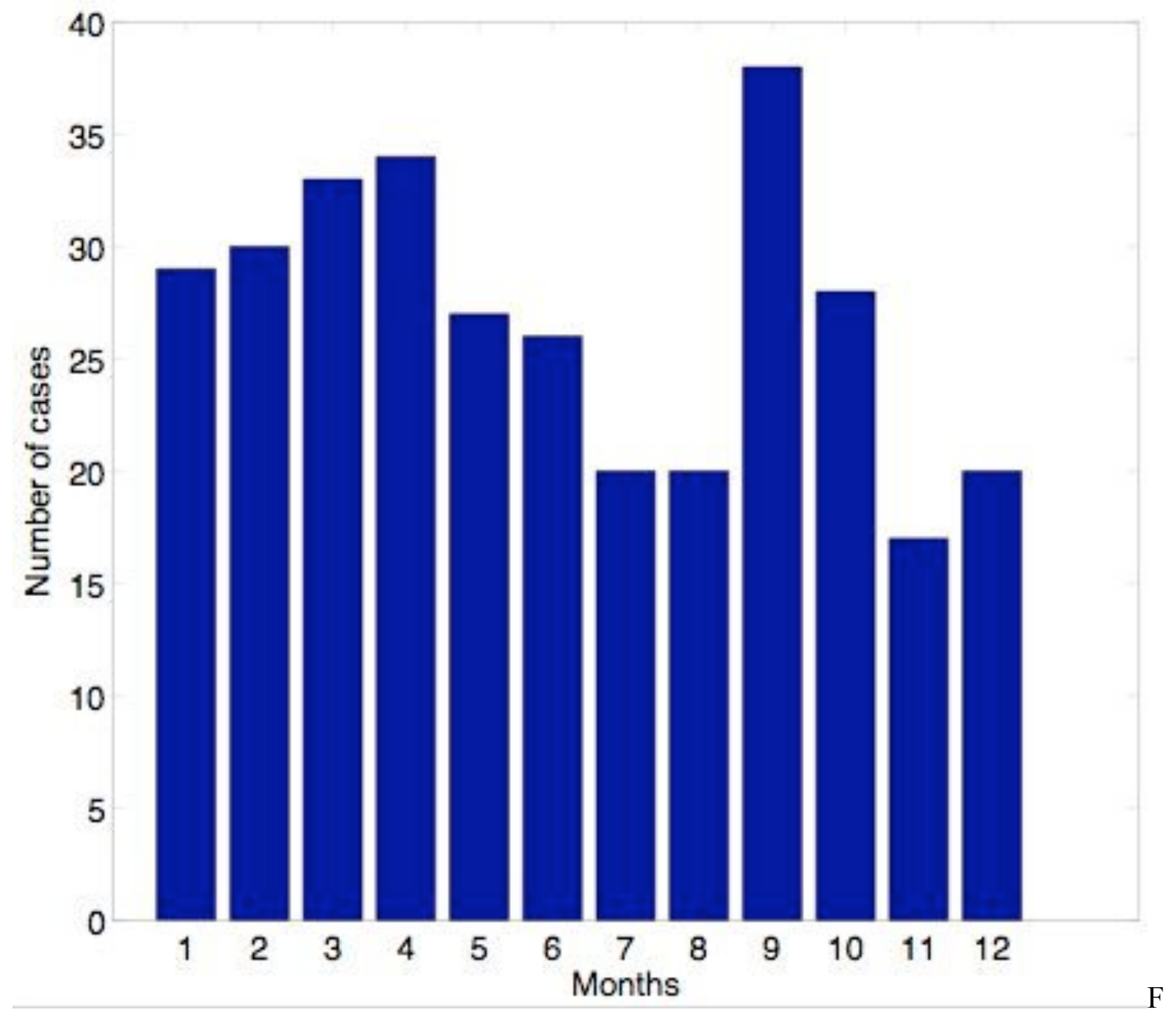

ig. 1 : Distribution of ice cloud observations over an annual cycle during the 2002-2004 period. 

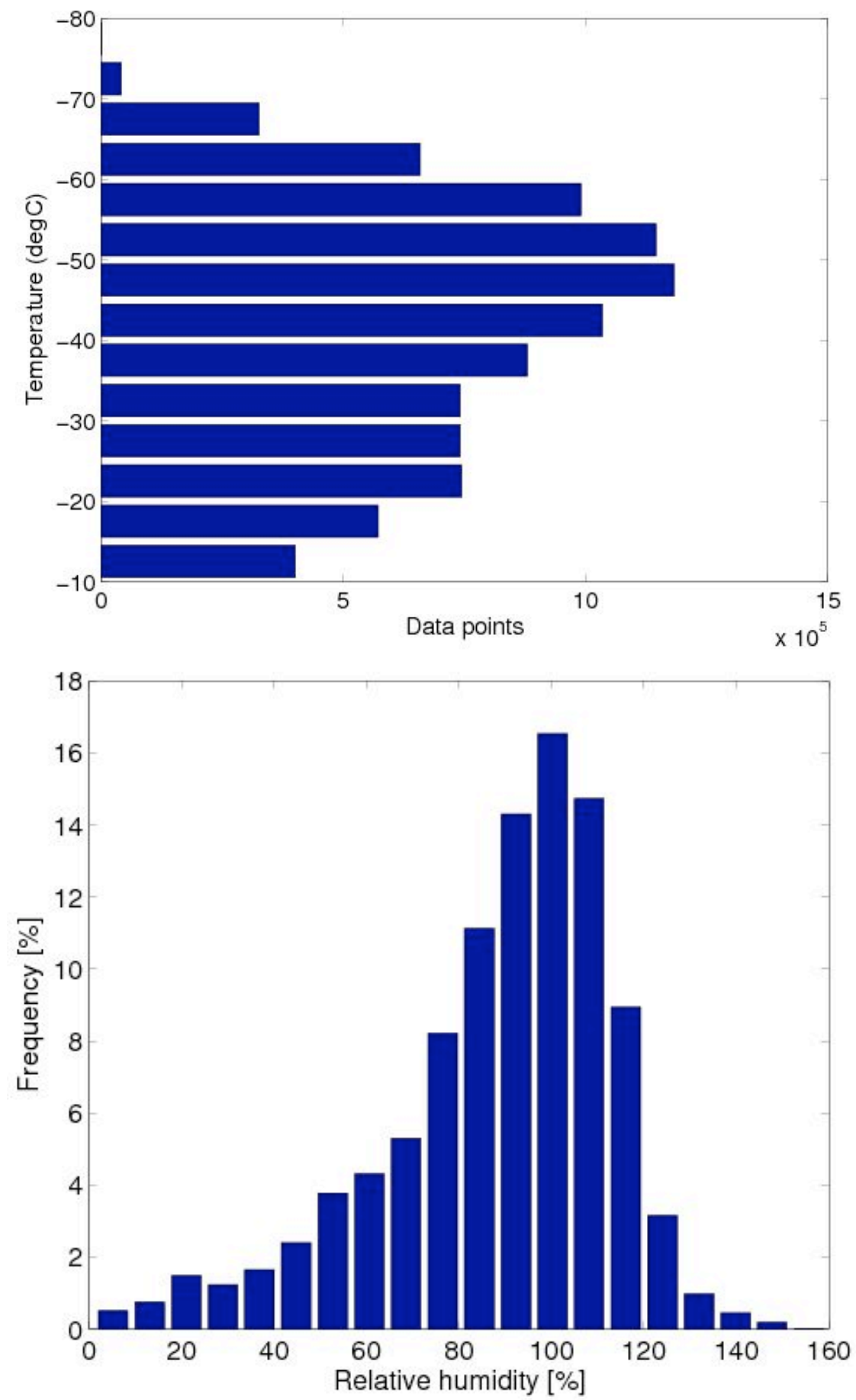

Fig 2 : Distribution of data points observed in ice clouds as a function of (a) atmospheric temperatures and (b) relative humidity with respect to ice. 

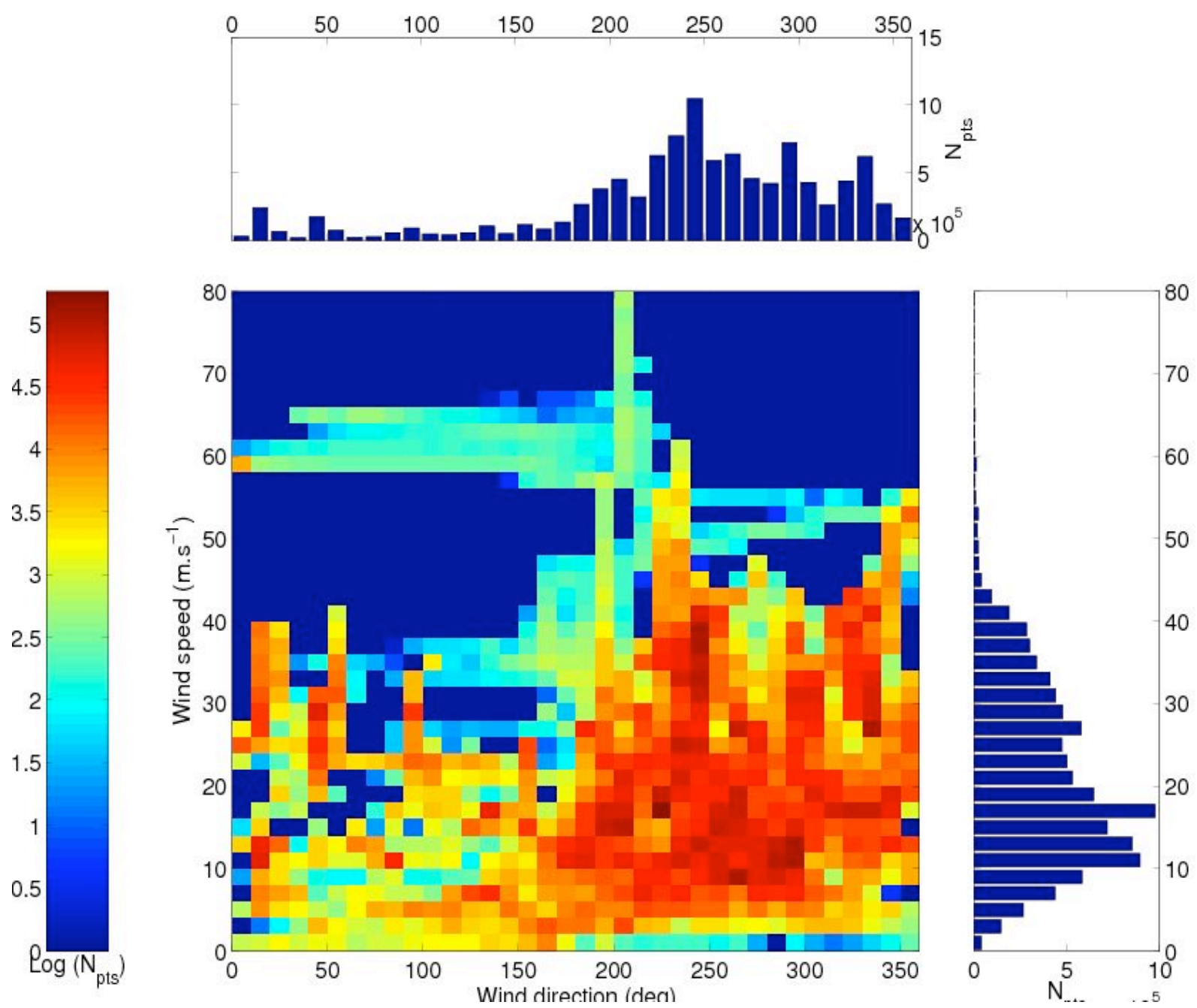

Fig. 3 : (a, top panel) Distribution of lidar data points observed in ice clouds as a function of

wind direction. (b, right panel) : Same as (a), as a function of wind speed. (c, center panel) same as a, as a function of wind direction (x axis) and speed (y axis), in logarithmic color scale. 

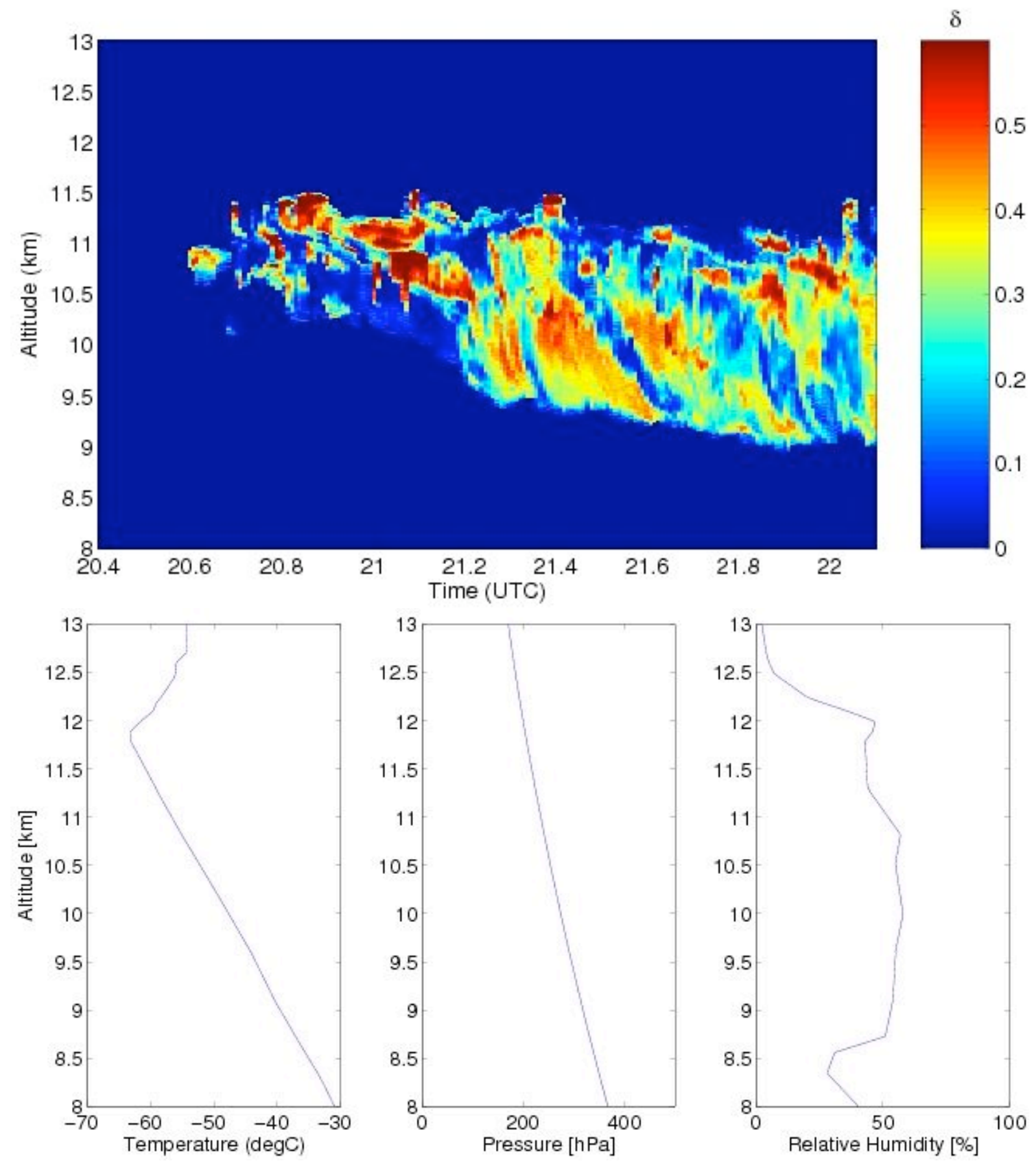

Fig 4 (a) : Observations of lidar depolarization ratio as a function of time and altitude for the June $2^{\text {nd }} 2004$ case (top panel). (b) Profiles of temperature $\left({ }^{\circ} \mathrm{C}\right)$, pressure $(\mathrm{hPa})$ and relative humidity (\%) as a function of altitude, from Trappes radiosoundings at 23:06 (bottom panel). 


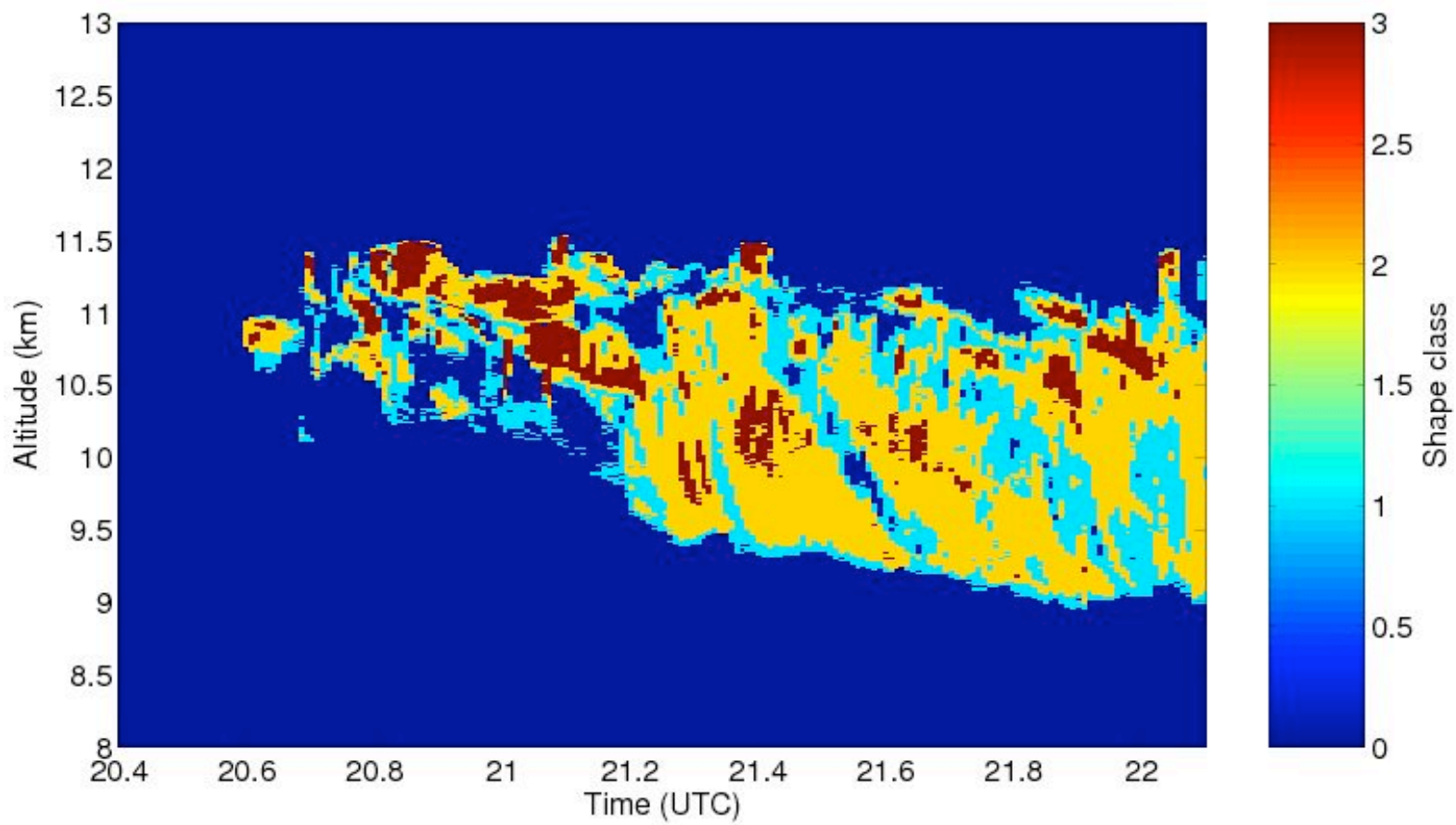

Fig 4c : Results of the shape classification technique as a function of time and altitude for the June $2^{\text {nd }} 2004$ case. 


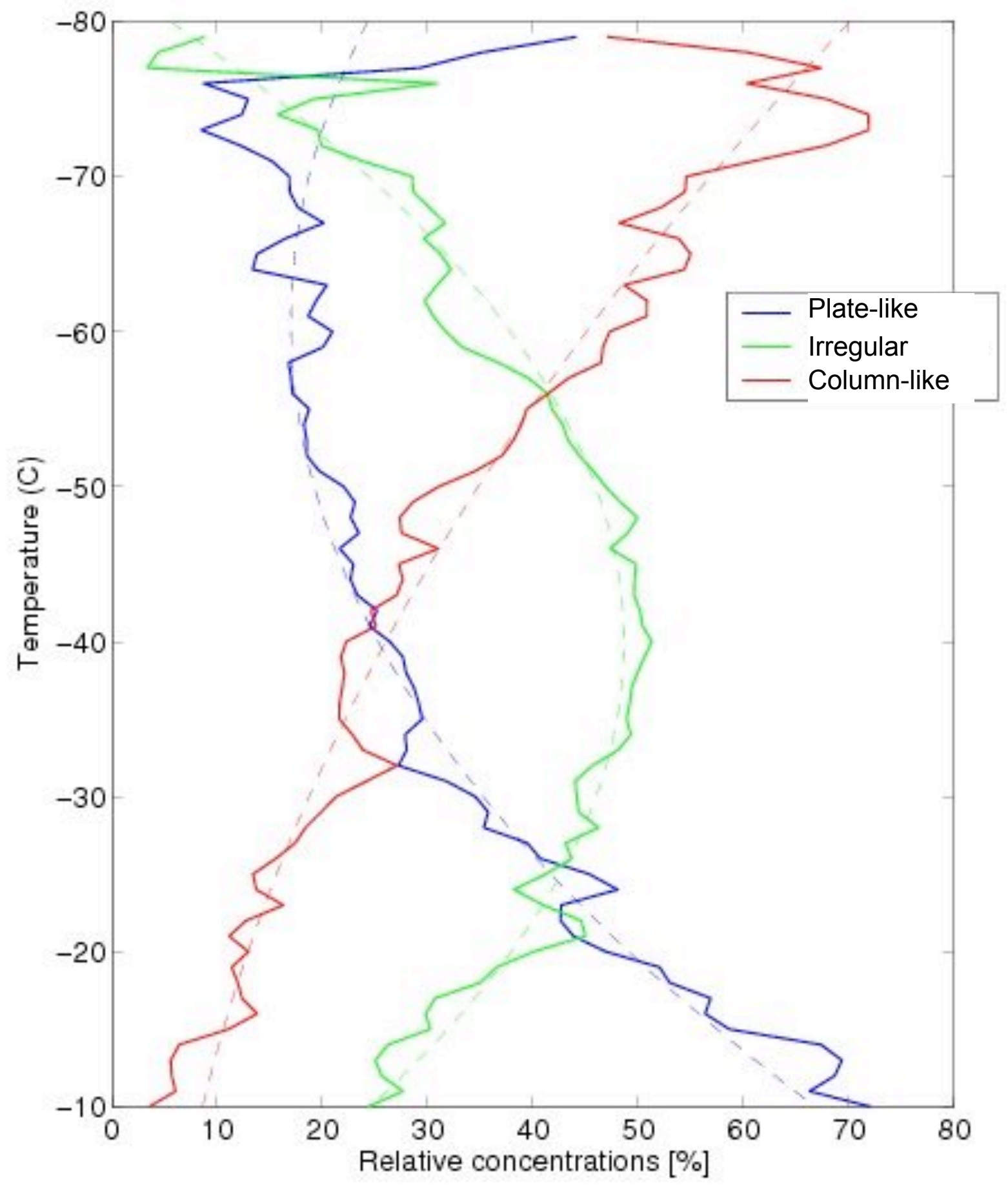

Fig. 5 : Distribution of shape class relative concentrations as a function of atmospheric temperature, with $2^{\text {nd }}$-order polynomial regression (dashed lines). 


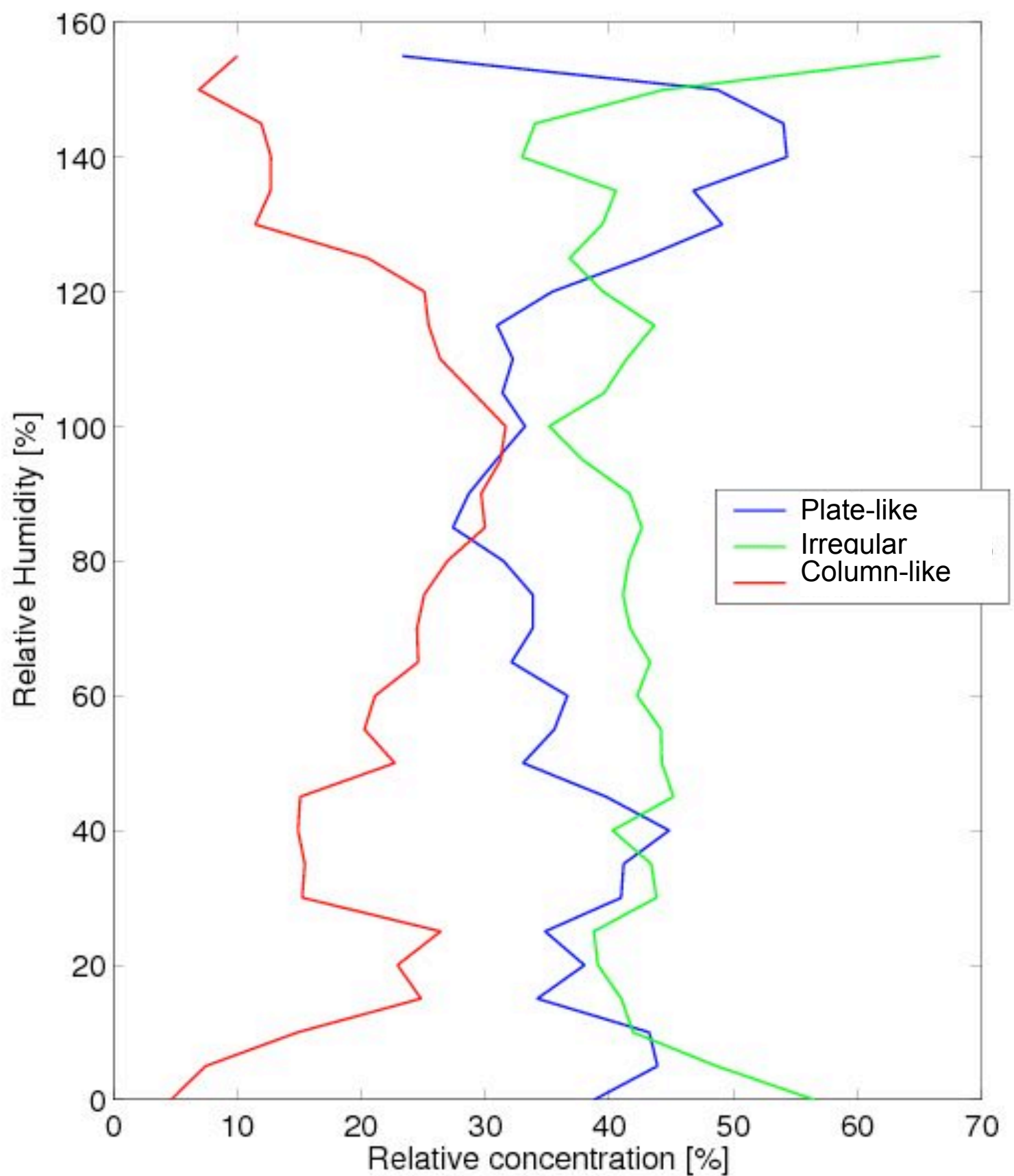

Fig. 6 : Distribution of shape class relative concentrations as a function of Relative Humidity with respect to ice. 


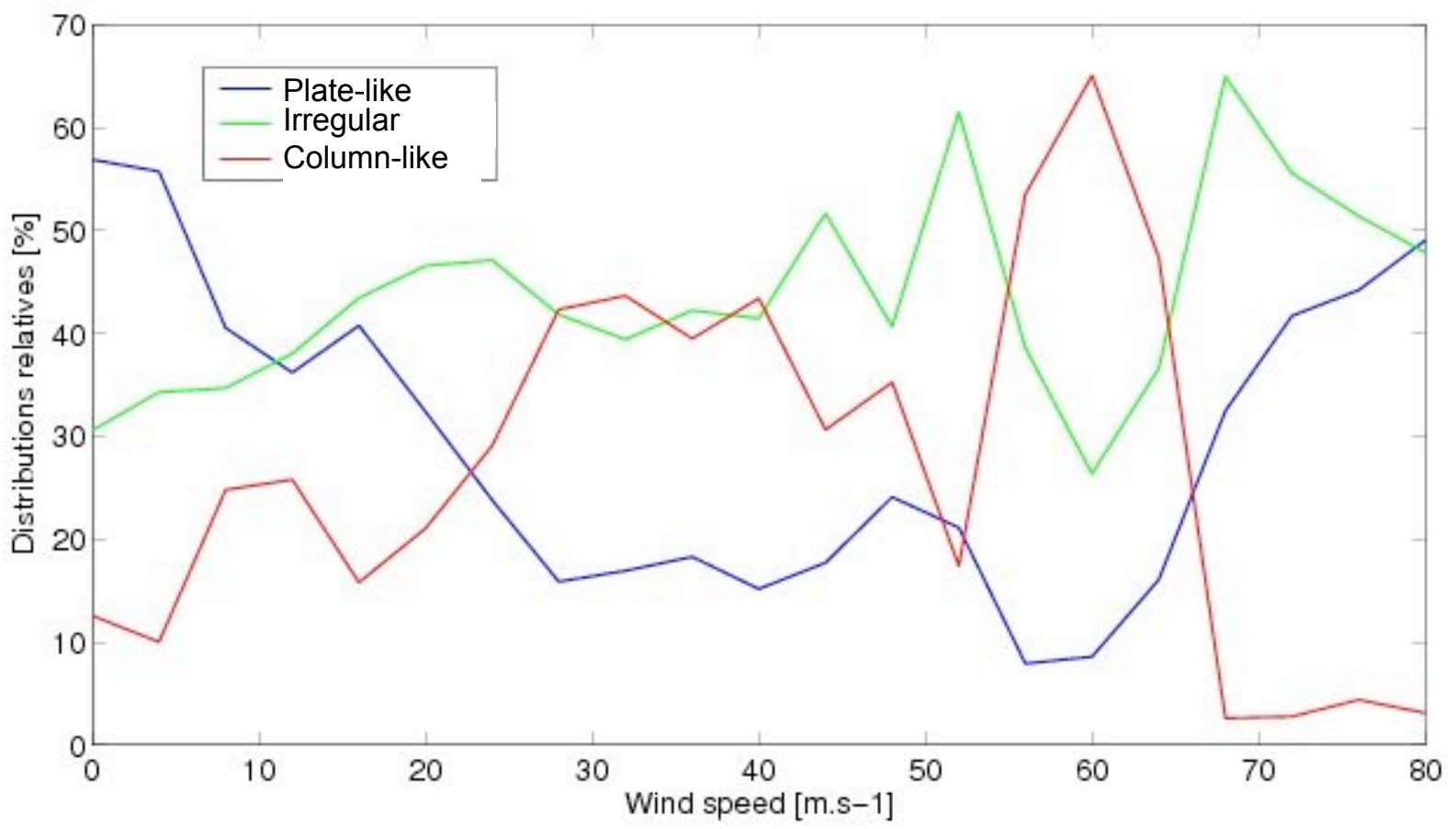

Fig. 7 : Distribution of shape class relative concentrations as a function of wind speed. 


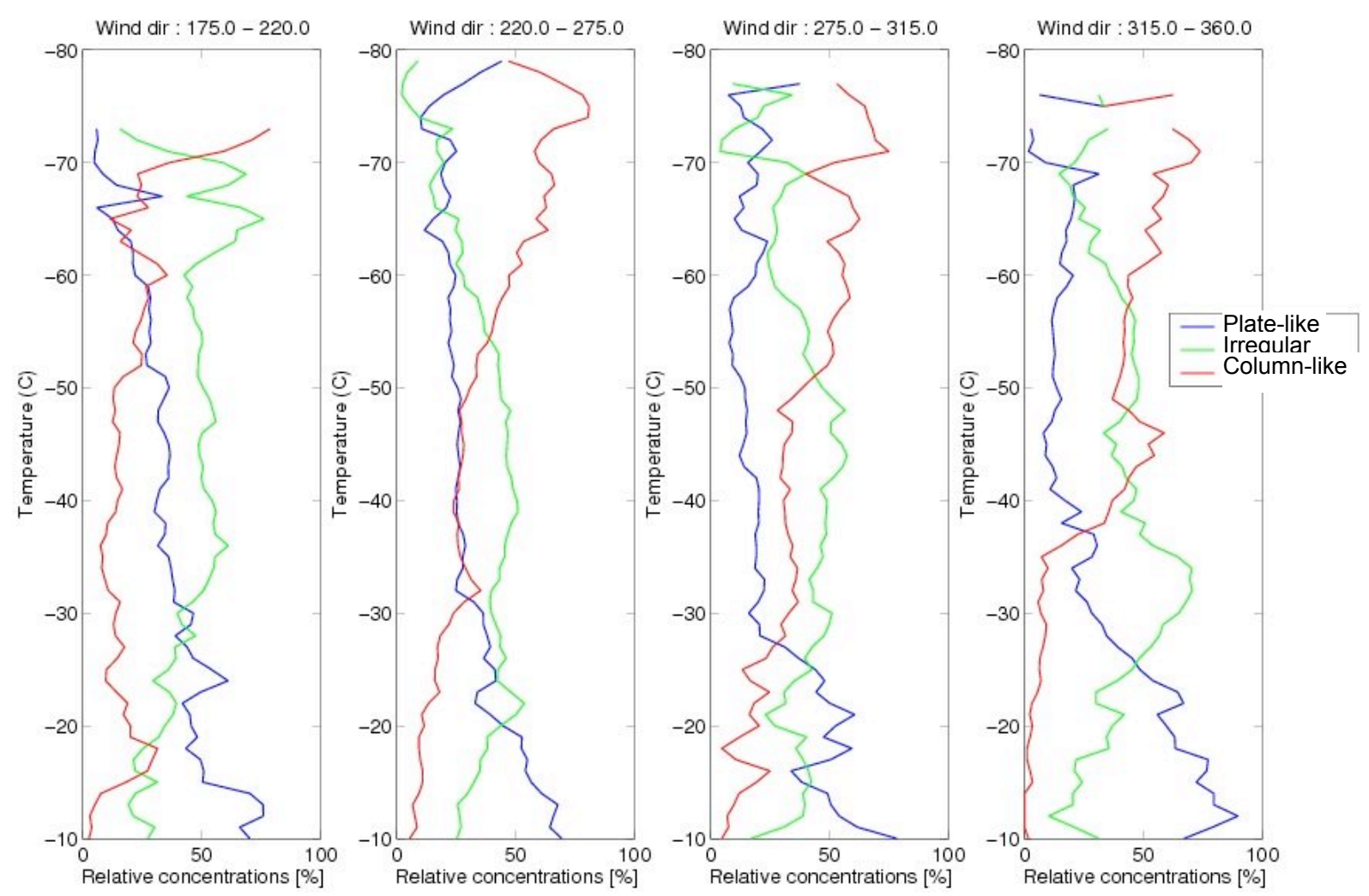

Fig. 8 : Distribution of shape class relative concentrations as a function of temperature, for wind directions (a) between $175^{\circ}$ and $225^{\circ}(\mathrm{SSW})$, (b) between $220^{\circ}$ and $275^{\circ}$ (WSW), (c) between $275^{\circ}$ and $315^{\circ}(\mathrm{WNW})$ and (d) between $315^{\circ}$ and $360^{\circ}(\mathrm{NNW})$. 

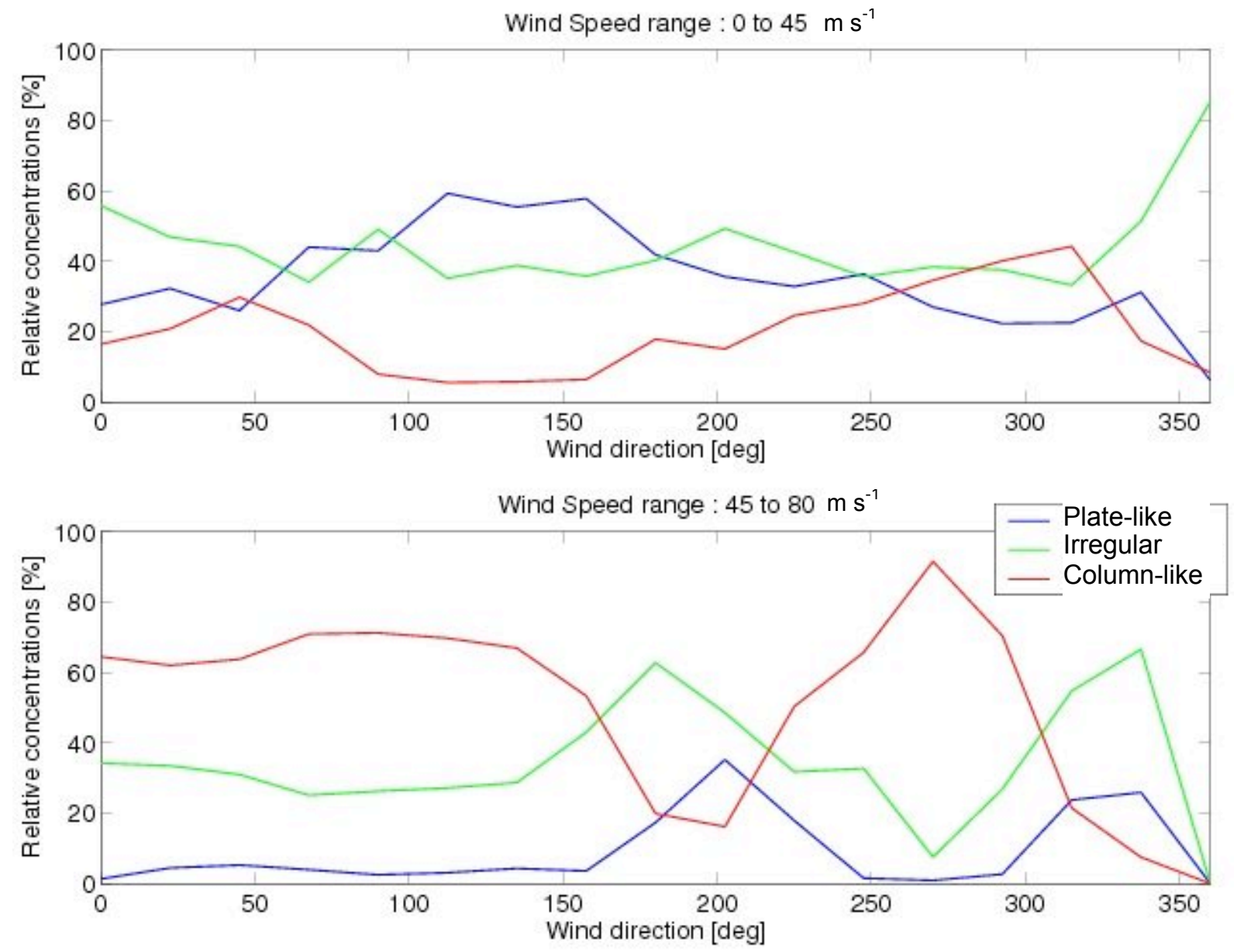

Fig. 9 : Distribution of shape class relative concentrations as a function of wind direction, for wind speeds (a) below $45 \mathrm{~m} \cdot \mathrm{s}^{-1}$ and (b) above $45 \mathrm{~m} \cdot \mathrm{s}^{-1}$. 